\title{
Parents' Practices and Barriers in Reducing Aflatoxins Contamination in Complementary Foods for Children in Central Regions of Tanzania
}

\author{
Selestin Joseph Ngoma ${ }^{1,2, *}$, Bendantukuka Tiisekwa ${ }^{1}$, Agatha Fabian Ngowi², \\ Secilia Kapalata Ngwashemi ${ }^{2}$, Leonard Kamanga Katalambula ${ }^{2}$ \\ ${ }^{1}$ Department of Food Technology, Nutrition and Consumer Sciences, Sokoine University of Agriculture, Morogoro, Tanzania \\ ${ }^{2}$ Department of Public Health, The University of Dodoma, Dodoma, Tanzania \\ Email address: \\ selengoma@yahoo.com (S. J. Ngoma), Selestin.ngoma@udom.ac.tz (S. J. Ngoma), tiisekwa@suanet.ac.tz (B. Tiisekwa), \\ btiisekwa@yahoo.co.uk (B. Tiisekwa), agywin2009@gmail.com (A. F. Ngowi), mwatty92@yahoo.com (S. K. Kapalata), \\ katalambula@gmail.com (L. K. Katalambula) \\ ${ }^{*}$ Corresponding author
}

\section{To cite this article:}

Selestin Joseph Ngoma, Bendantukuka Tiisekwa, Agatha Fabian Ngowi, Secilia Kapalata Ngwashemi, Leonard Kamanga Katalambula. Parents' Practices and Barriers in Reducing Aflatoxins Contamination in Complementary Foods for Children in Central Regions of Tanzania. Journal of Health and Environmental Research. Vol. 6, No. 3, 2020, pp. 68-78. doi: 10.11648/j.jher.20200603.14

Received: May 20, 2020; Accepted: June 15, 2020; Published: July 6, 2020

\begin{abstract}
Contamination of complementary foods by aflatoxin is a serious public health threat that requires attention to ensure that proper actions are taken to limit its health effects. A cross-sectional study was conducted to assess parents' practices and barriers associated with reducing aflatoxins contamination in complementary foods among parents with children aged 6-23 months in central regions of Tanzania. Semi-structured questionnaire (364) respondents and focus group discussion (FGD) with (121) respondents were used to collect data. The information collected included socio-demographic variables, parents' barriers, and actions to mitigate aflatoxin contamination and its reduction strategies. The results of the fitted model revealed that among proposed predictors of barriers for proper processing of grains/nuts to reduce spoilage/aflatoxin/ mould contamination at home, only a number of children that a participant had was statistically significant. The family with 3-7 children, the estimated odds that the barrier is time consuming rather than costly, was 0.305 times the estimated odds for the family with 1-2 children. This means that parents with 3-7 children were less likely to report that time consumed was the barrier rather than the costs involved in comparison to parents with 1-2 children. On the other hand, the estimated odds for parents with 3-7 children that the barrier reduces food quantity instead of costs, was equal to 2.389 times the estimated odds for parents with 1-2 children. The results of multiple logistic regression model for applying traditional fungicides/pesticides for storing crops showed that respondents aged above 34 years $(\mathrm{OR}=0.576,95 \%$ CI: $0.342-0.969)$ were significantly few in applying traditional fungicides/pesticides for storing crops than those respondents aged less or equal to 34 years old. The respondents with no/incomplete primary education $(\mathrm{OR}=2.872,95 \% \mathrm{CI}: 1.283-6.427)$ and primary education $(\mathrm{OR}=2.256,95 \%$ CI: 1.194-4.264) were significantly more in applying traditional fungicides/pesticides for storing crops than never been to school respondents. FGDs revealed that drying crops before taking them for storage, use of traditional herbs for example ash and mud applied/smeared/sprayed on the grain before and during storage was used to preserve crops/grain against fungi. It was revealed that no any formal or informal education had been provided about fungi contamination, and even control, rather, the respondents were generally preventing (mould) aflatoxins through experience. Therefore, there is a need to educate the community on good agricultural practices for the better food safety and health of the community in general.
\end{abstract}

Keywords: Aflatoxin, Parents, Barriers, Complementary Foods, Central Tanzania 


\section{Introduction}

Aflatoxin, a fungal toxin that commonly contaminates nuts, maize and other types of cereals is notorious not only for the havoc it wreaks on crops but those it inflicts on humans and animals as well [1-4]. This fungus is capable of attacking crops during production, harvest, storage, and even during processing and is now recognized as one of the biggest challenges to food and nutrition security, health and trade across the African continent [2, 5-8]. It is estimated that more than 5 billion people in developing countries worldwide are chronically exposed to aflatoxins. The effects to this exposure includes liver cirrhosis, intestinal dysfunction, immune suppression and increased susceptibility to some infectious diseases including HIVAIDS, and maternal and child health problems such as anaemia, malnutrition, stunting and wasting [9-13].

According to researchers in animals [1, 14-17], aflatoxins reduce productivity of healthy livestock through ingestion of contaminated feed; once ingested, the fungus causes a decrease in production of milk and eggs and it also leaves toxic residues in dairy, meat and poultry products and causes serious illness in almost all animals. The occurrence of aflatoxins is influenced by certain environmental factors; hence the extent of contamination varies with geographic location, agricultural and agronomic practices, and the susceptibility of commodities to fungal invasion during pre-harvest, storage, and/or processing periods $[6,8,18-20]$. Aflatoxins have received greater attention than any other mycotoxins because of their demonstrated potent carcinogenic effect in susceptible laboratory animals and their acute toxicological effects in humans $[9,17,21,22]$. As it is obvious that absolute safety can never achieved, many countries have attempted to limit exposure to aflatoxins by imposing regulatory limits on commodities intended for use as food and feed [23-26].

The aflatoxins B1, B2, G1, G2 plus two additional metabolic products, aflatoxins M1 and M2, are of significance as direct contaminants of foods and feeds [19, 27]. Aflatoxin $B 1$ is the most potent of the aflatoxins. Aflatoxins have been rated as class $1 \mathrm{~A}$ human carcinogens and OTA as a possible human carcinogen (group 2B; 1) by the International Agency for Research of Cancer [27-29]. These toxins have closely similar structures and form a unique group of highly oxygenated, naturally occurring heterocyclic compounds [27-29].

Aflatoxin contamination of crops used in preparation of complementary foods in fields of farmers in the central regions of Tanzania can be significantly reduced by following good agricultural practices, implemented from planting, drying and storage. Studies to assess multiple mycotoxin contamination in stored maize and the association between aflatoxins (AFs) and fumonisins (FBs) contamination of maize and traditional post-harvest practices have been done in several parts of rural Tanzania $[8,20,30]$. Results from the mentioned study indicated high levels of aflatoxins (AFs) and fumonisins (FBs) among other mycotoxins with the co-occurrence in $45 \%$ of the samples. AFs and FBs were detected in $50 \%$ at levels of up to 1081 $\mu \mathrm{g} / \mathrm{kg}$ and $73 \%$ at levels up to $38217 \mu \mathrm{g} / \mathrm{kg}$, respectively. Other studies in Tanzania have reported occurrence of these toxins at significant levels $[31,32]$. In a study conducted by Kimanya et al [31] eighteen percent of the home-grown maize samples were contaminated with aflatoxins at levels up to $158 \mu \mathrm{g} / \mathrm{kg}$, with $12 \%$ of these above the Tanzanian limit of $10 \mu \mathrm{g} / \mathrm{kg}$. Other studies assessed aflatoxin and fumonisin exposures using validated exposure biomarkers and estimated their associations with growth [33]. In addition, studies in Tanzania reported high exposure of infants and young children to AFs and FBs through maize based diet [34] and AFM1 [35] and FB1 [34] through breast milk from mothers whose main diet was maize.

Despite the above mentioned incidences of high levels of mycotoxins and associated health effects of aflatoxins in human, no study has been conducted to assess the association between awareness, local barriers of reducing aflatoxin contamination of complementary foods and traditional practices used to control aflatoxin (fungi) in crops in central Tanzania. This knowledge is vital to the community in order to develop strategies for reducing aflatoxins in crops that are used as ingredients in preparing complementary foods. This study was undertaken to explore associations between awareness, local barriers and traditional practices in reducing risks of aflatoxin contamination in grains which are used in the preparation of complementary foods in rural Tanzania.

\section{Research Methodology}

\subsection{Study Areas}

This study was conducted in four districts of Central Tanzania namely, Chamwino and Bahi in Dodoma Region (Figure 1), Manyoni and Ikungi in Singida Region (Figure 2). The two regions experience low rainfall and short rainy seasons which are often erratic with long periods of drought. Selection of study area was triggered by environmental characteristics, The two regions have semi-arid condition which is characterized by high temperature during the day (up to $35^{\circ} \mathrm{C}$ ) and low temperature (as low as $10^{\circ} \mathrm{C}$ ) during the night. Both high temperature and humidity favour the growth of fungi thus signalling possibility of aflatoxins production in improperly stored crops [18]. In addition, preliminary results from the cereals (maize, sorghum and millet) tests by the CDC showed aflatoxins contamination cases ranged from 10$51,100 \mathrm{ppb}$ which was remarkably above the tolerant limit to human being $[4,36]$. In Dodoma region, (Kondoa, Chemba, Dodoma, Chamwino districts) and Manyara (Kiteto District), the outbreak of aflatoxin contamination in cereals was revealed where 68 people were reported to have been exposed to the unknown poison. Out of those exposed people, 20 deaths making a case fatality rate of $30 \%$ were reported due to liver failure with the majority more than $50 \%$ 
of the affected being children aged below 15 years old $\left[\begin{array}{ll}4, & 36\end{array}\right]$.

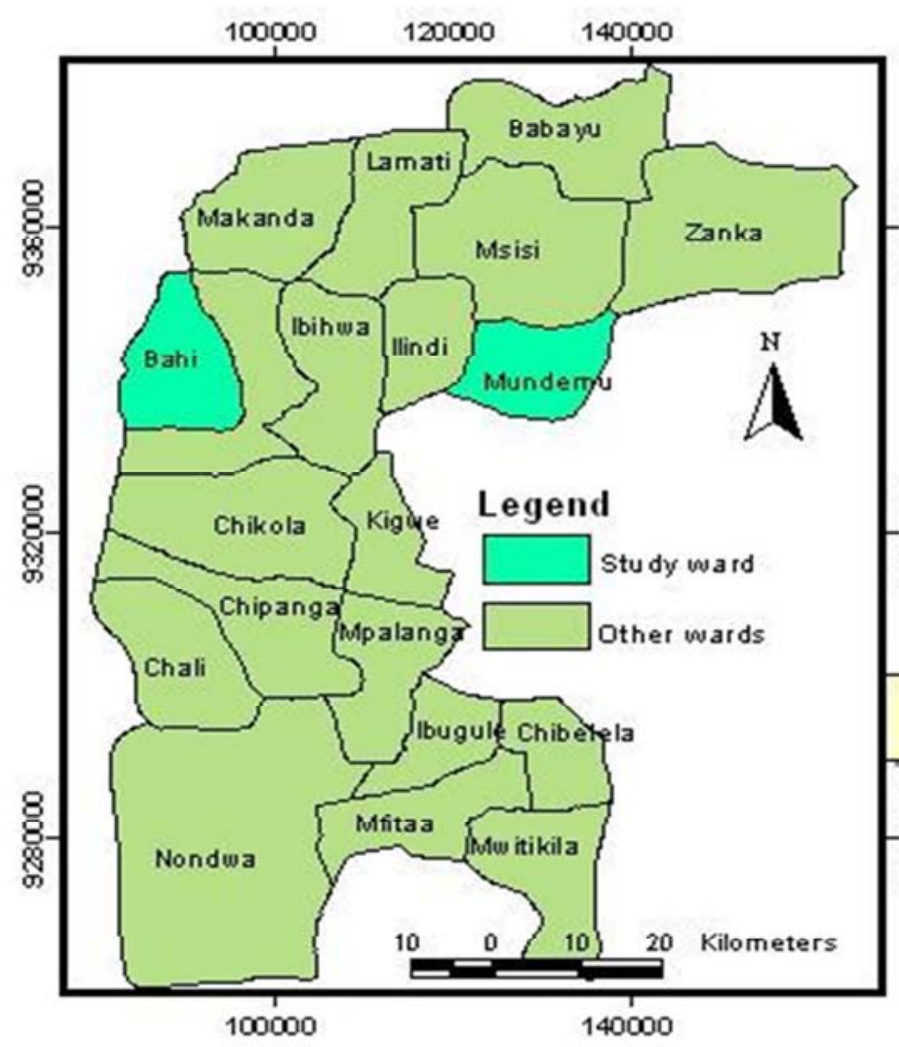

$\mathscr{8}$
-8
8


0
8
8

\section{BAHI DISTRIC T}

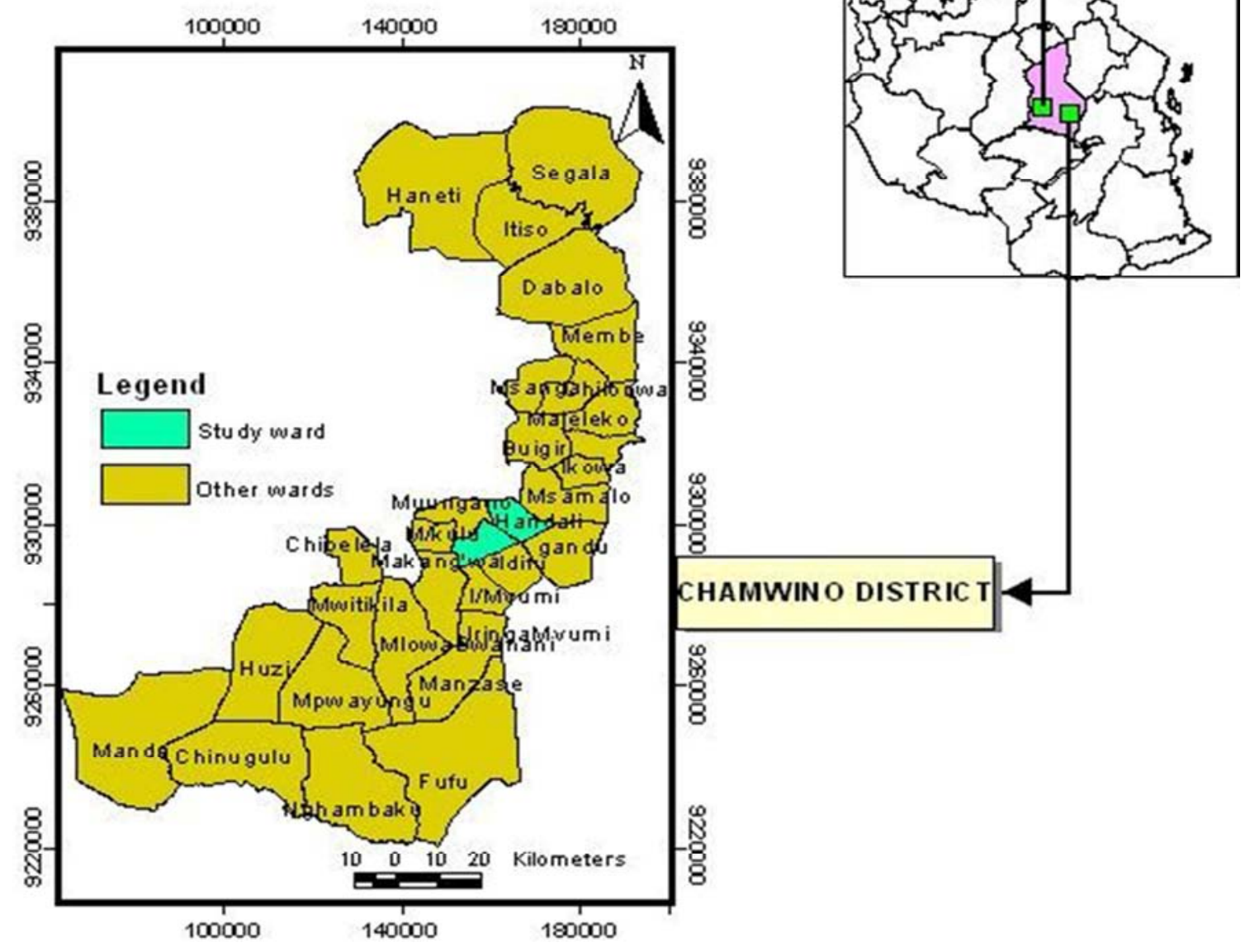

Figure 1. The Maps of Bahi and Chamwino Districts in Dodoma Region Showing Study Areas. 


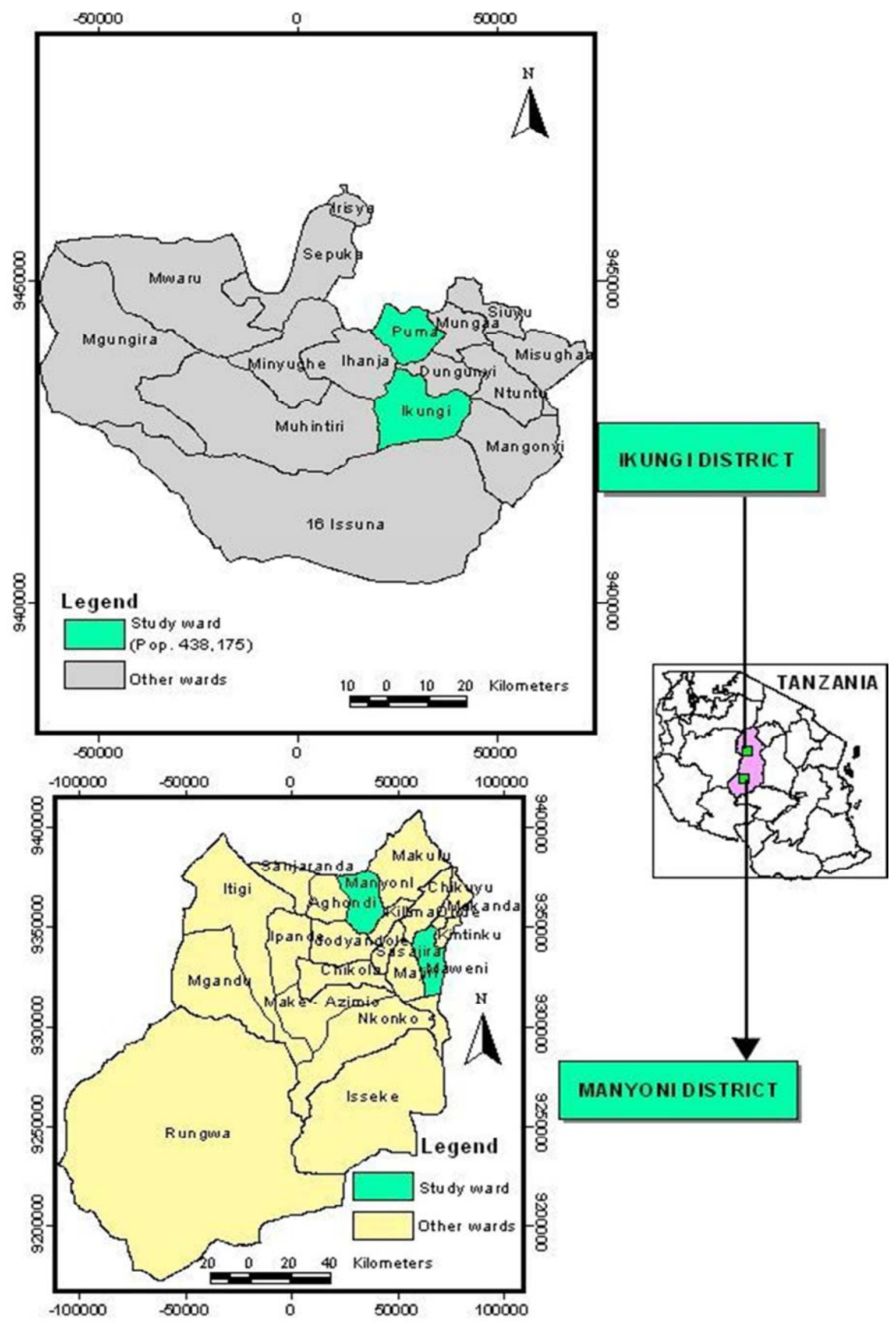

Figure 2. The Maps of Ikungi and Manyoni Districts in Singida Region Showing Study Areas. 


\subsection{Study Design}

The study employed analytical cross-sectional study design with both quantitative and qualitative approach. The cross-sectional design also allows one to either use the entire population or a subset.

\subsection{Study Population}

Parents/caregivers of the children aged between 6 to 23 months who resided in the study area for more than six months were included in the study. Parents/caregivers who were seriously ill during data collection were excluded in the study.

\subsection{Sample Size and Sampling Procedure}

A total sample size of 364 participants were obtained by applying the single proportional formula $\left(n=\left(\mathrm{t}^{2}\right) \mathrm{p}(1-\mathrm{p}) / \mathrm{m}^{2}\right)$ [37]. This formula was used in the Statcalc programme of Epi Info Version 6 [38] with standard normal deviate value (set at 1.96 which corresponded to the 95\% confidence interval level) and margin error, the degree of accuracy taken to be $5 \%$ and the proportion of parents/caregivers who have been aware of aflatoxin taken to be 33\%) from [39].

A multistage sampling technique was used to select a total of 364 parents/caregivers with children aged between 6-23 months to participate in the study. The process involved simple random sampling at district,, ward and village/street up to household level. Bahi District consists of 20 wards and out of these, two wards were selected randomly (Bahi and Mundemu) and from these wards, one village/street was selected from each (Bahi Sokoni and Mundemu respectively). Chamwino District consists of 32 wards and out of these two wards were selected randomly (Handali and Mvumi Mission) and from those two wards, one village/street was selected from each (Handali and Ndebwe respectively). Manyoni District consists of 30 wards and out of these, two wards were selected randomly (Manyoni and Maweni) and from those two wards, one village/street was selected from each (Manyoni and Maweni respectively). Ikungi District consists of 26 wards and out of these, two wards were selected randomly (Ikungi and Puma) and from these wards, one village/street was selected from each (Ikungi and Puma respectively). In case a household had more than one child aged between 6-23 months, one-household-one child was randomly selected to avoid clustering of information. In Dodoma and Singida regions, there were 182 households for the study, respectively. In each household, either men or women who were parents or caregivers of children aged between 6 to 23 months were recruited from each village or street.

\subsection{Data Collection Techniques and Procedures}

Data collection tools was prepared in English and translated into Kiswahili language. Structured questionnaire with both open and close-ended questions was used for collecting information regarding socio-demographic of parents/caregivers and children and practices of community in aflatoxin contamination. A pilot study was conducted with 30 parents/caregivers in one village not included in the study before the actual data collection process to observe whether the tools could be fit in obtaining required information. Two research assistant collected data via face to face interview. Both research assistant were nurses with diploma level who underwent training for two days on data collection procedure. The research assistants were regularly supervised by principal investigator for proper data collection. Filled questionnaires were checked for completeness and consistency daily.

Qualitative data were collected by using the Krueger methodology for conducting focus group discussions (FGDs) [40]. The FGDs were conducted by using a checklist to allow the researcher guide the sessions and obtain the participants' views. Participants (including parents or caregivers with children aged between 6 to 23 months) in Focus Group Discussion (FGD) were purposefully selected from the four randomly selected districts. These were the criteria that were used in inclusion and exclusion of participants. One pair of research assistants (male and female) facilitated the FGDs by using a discussion guide and the principal researcher served as the assistant moderator. Another pair took notes during the FGDs. Information was collected by research assistants through 17 Focus Group Discussions (FGDs) with 121 participants (105 females and 16 males). The composition of all 17 FGDs was six (6) participants except six groups which had nine participants each and one group which had seven participants. The discussions were held in class rooms, office of village leaders or office of ward executive officer. The information collected was on community actions to prevent aflatoxins (mould) contamination in crops, education provided about aflatoxin/fungus contamination and control to the community and also personal experiences about aflatoxin contaminations in complementary foods. The interview lasted for approximately 40 minutes for each session. All the interviews were audio recorded after obtaining the consent from participants and then the tapes were transcribed and translated into English by the principal researcher.

\subsection{Data Analysis}

The IBM SPSS ${ }^{\circledR}$ software version 21.0 was used for data entry and analysis after cleaning. Descriptive statistics was used to analyze demographic characteristic and presented by using frequency, percentage and table's. The Baseline Logit Model (BLM) was adopted to study the association between the barriers for proper processing of grains/nuts to reduce spoilage at home and set of proposed predictors. The outcome variable (barrier) had three categories: Time consuming; its ability to reduce food quantity and cost. The multiple logistic regression model (LRM) was employed to determine the association between respondents' applying traditional fungicides/pesticides for storing crops to reduce 
aflatoxin/ fungi contamination to the crops during storage and set of proposed predictors in this study. A 5\% level of significance was used throughout the study and an independent variable with a p-value less than 0.05 was considered as statistically (significant) associated with outcome variable. For the qualitative part, coding was done using NVivo 7 software. The NVivo package has the ability to code and sort narrative data, interface with SPSS, and has good modelling facility and is user friendly [40]. It also combines best the NUD*IST computer software package with much more flexibility friendly [41]. The FGDs were analysed by using Thematic Content Analysis method. All components of the study received University Research and Publication approval Ref: SUA/CB/26.

\section{Results}

\subsection{Socio-Demographic Characteristics of Respondents}

Results in Table 1 show the distribution of parents/caregivers by socio-demographic characteristics in Bahi, Chamwino, Ikungi, and Manyoni Districts. The age of parents/caregivers ranged from 17 to 80 years with mean age (SD) of $30(8.3)$ years, $270(74.2 \%)$ of the respondents were aged 34 years or below while respondents aged above 34 years were 94 (25.8\%). Mothers made up 331 (90.9\%) of the respondents.

Table 1. Distribution of Parents/caregivers by Socio-demographic Characteristics.

\begin{tabular}{lll}
\hline Characteristics & Number & (\%) \\
\hline Age group (Years) & & \\
$\leq 34$ & 270 & $(74.2)$ \\
$>34$ & 94 & $(25.8)$ \\
$\begin{array}{l}\text { Number of children } \\
1-2\end{array}$ & 180 & $(49.5)$ \\
$3-7$ & 184 & $(50.5)$ \\
Monthly income (US\$) & & \\
\hline
\end{tabular}

\begin{tabular}{lll}
\hline Characteristics & Number & $\mathbf{( \% )}$ \\
\hline$\leq 22.8$ & 256 & $(70.3)$ \\
$>22.8$ & 108 & $(29.7)$ \\
Level of education & & \\
Never been to school & 64 & $(17.6)$ \\
Partial primary & 49 & $(13.5)$ \\
Primary & 204 & $(56)$ \\
Partial secondary & 18 & $(4.9)$ \\
Secondary & 29 & $(7.9)$ \\
Respondents' occupation & & \\
Farmers & 287 & $(78.8)$ \\
House wives & 32 & $(8.8)$ \\
Employees & 10 & $(2.7)$ \\
Petty traders & 35 & $(9.6)$ \\
Marital status & & \\
In Union & 272 & $(74.7 \%)$ \\
Not in Union & 92 & $(25.3 \%)$ \\
\hline
\end{tabular}

\subsection{Barriers for Proper Processing of Grains/Nuts to Reduce Spoilage/ Aflatoxins}

Out of 364 respondents, $242(66.5 \%)$ reported that costs involved was the barrier for proper processing of grains/nuts to reduce spoilage/aflatoxin/mould (which they call fangasi) at home while time consumed and reducing food quantity had equal proportion (16.8\%). The results of the fitted model (Table 2) revealed that among proposed predictors of barriers for proper processing of grains/nuts to reduce spoilage/aflatoxin/ mould at home, only the number of children that a participant had was statistically significant. For parents with 3-7 children, the estimated odds that the barrier is time consuming rather than costly was 0.305 times the estimated odds for subjects with 1-2 children. This means that parents with 3-7 children were less likely to report that time consumed was the barrier instead of costs involved in comparison to with 1-2 children. On the other hand, the estimated odds for parents with 3-7 children that the barrier is reduced food quantity instead of costs involved was equal to 2.389 times the estimated odds for parents with 1-2 children.

Table 2. Parameter estimates and odds ratios (OR) of barriers for proper processing of grains/nuts to reduce spoilage/aflatoxin.

\begin{tabular}{|c|c|c|c|c|c|}
\hline Variable & Cases & Barriers & Estimate (SE) & OR & P-Value \\
\hline & Yes & Time consuming & $0.4240(0.3669)$ & 1.528 & 0.2478 \\
\hline \multirow[t]{4}{*}{ Awareness } & Yes & Reduces food quantity & $-0.6489(0.4554)$ & 0.523 & 0.1541 \\
\hline & No & It is costly & Reference & Reference & Reference \\
\hline & Yes & Time consuming & $-0.0836(0.4184)$ & 0.920 & 0.8416 \\
\hline & No & It is costly & Reference & Reference & Reference \\
\hline \multirow[t]{3}{*}{ Number of Children } & $3-7$ & Time consuming & $-1.1885(0.3264)$ & 0.305 & 0.0003 \\
\hline & $3-7$ & Reduces food quantity & $0.8711(0.3155)$ & 2.389 & 0.0058 \\
\hline & $1-2$ & It is costly & Reference & Reference & Reference \\
\hline \multirow[t]{3}{*}{ Age (Years) } & $>34$ & Time consuming & $-0.5190(0.3784)$ & 0.595 & 0.1701 \\
\hline & $>34$ & Reduces food quantity & $-0.0348(0.3386)$ & 0.966 & 0.9182 \\
\hline & $\leq 34$ & It is costly & Reference & Reference & Reference \\
\hline \multirow[t]{3}{*}{ Monthly Income (US\$) } & $>22.8$ & Time consuming & $-0.3242(0.3732)$ & 0.723 & 0.3850 \\
\hline & $>22.8$ & Reduces food quantity & $0.1706(0.3499)$ & 1.186 & 0.6258 \\
\hline & $\leq 22.8$ & It is costly & Reference & Reference & Reference \\
\hline \multirow[t]{7}{*}{ Education Level } & Partial Primary & Time consuming & $-0.0152(0.5395)$ & 0.985 & 0.9776 \\
\hline & Partial Primary & Reduces food quantity & $0.0608(0.5009)$ & 1.063 & 0.9035 \\
\hline & Primary & Time consuming & $-0.2471(0.4095)$ & 0.781 & 0.5462 \\
\hline & Primary & Reduces food quantity & $-0.1829(0.3902)$ & 0.833 & 0.6392 \\
\hline & Partial Secondary & Reduces food quantity & $-0.0172(0.7546)$ & 0.983 & 0.9819 \\
\hline & Secondary & Time consuming & $0.6592(0.5642)$ & 1.933 & 0.2426 \\
\hline & Secondary & Reduces food quantity & $-1.8133(1.0933)$ & 0.163 & 0.0972 \\
\hline
\end{tabular}




\begin{tabular}{llllll}
\hline Variable & Cases & Barriers & Estimate (SE) & OR & P-Value \\
\hline \multirow{3}{*}{ Marital Status } & Never been to School & It is costly & Reference & Reference & Reference \\
& In Union & Time consuming & $0.1710(0.3484)$ & 1.187 & 0.6235 \\
& In Union & Reduces food quantity & $0.1586(0.3591)$ & 1.172 & 0.6587 \\
& Not in Union & It is costly & Reference & Reference & Reference \\
\hline
\end{tabular}

\subsection{Application of Traditional Fungicides/Pesticides for Storing Crops}

It was reported that $221(60.7 \%)$ of the 364 participants were applying traditional pesticides for storing crops. The results of multiple logistic regression model for applying traditional fungicides/pesticides for storing crops (Table 3) showed that respondents aged above 34 years $(\mathrm{OR}=0.576$, 95\% CI: 0.342-0.969) were significantly less in applying traditional fungicides/pesticides for storing crops than respondents aged less or equal to 34 years. The respondents with partial primary education $(\mathrm{OR}=2.872,95 \% \mathrm{CI}: 1.283$ $6.427)$ and primary education $(\mathrm{OR}=2.256,95 \%$ CI: $1.194-$
4.264) were significantly more in applying traditional fungicides/pesticides for storing crops than the never been to school. However, respondents with partial secondary education $\mathrm{p}=0.7852$, $(\mathrm{OR}=0.845,95 \% \mathrm{CI}: 0.253-2.830)$ and secondary education $\mathrm{p}=0.8381,(\mathrm{OR}=0.882,95 \% \mathrm{CI}$ : 0.266 2.931) were not statistically significant, had less responses in applying traditional fungicides/pesticides for storing crops compared to those respondents who had never been to school. Other independents variables, namely awareness, number of children in the household, monthly income, occupation and marital status were not significantly associated with applying traditional pesticides/fungicides for storing crops since $\mathrm{p}>0.05$.

Table 3. Parameter estimates and odds ratios (OR) for applying traditional fungicides/pesticides for storing crops.

\begin{tabular}{|c|c|c|c|c|}
\hline Variable & Parameter Estimate (se) & OR & $95 \% \mathrm{CI}$ & P-Value \\
\hline \multicolumn{5}{|l|}{ Awareness } \\
\hline No & Reference & Reference & Reference & Reference \\
\hline Yes & $0.3056(0.2976)$ & 1.357 & {$[0.758-2.433]$} & 0.3045 \\
\hline \multicolumn{5}{|l|}{ Number of Children } \\
\hline 1-2 Children & Reference & Reference & Reference & Reference \\
\hline 3-7 Children & $-0.1980(0.2222)$ & 0.820 & {$[0.531-1.268]$} & 0.3729 \\
\hline \multicolumn{5}{|l|}{ Age (Years) } \\
\hline$>34$ & $-0.5524(0.2656)$ & 0.576 & {$[0.342-0.969]$} & 0.0376 \\
\hline \multicolumn{5}{|l|}{ Monthly Income (US\$) } \\
\hline - nno & Reference & Reference & Reference & Reference \\
\hline - วา० & $0.2772(0.2791)$ & 1.319 & {$[0.764-2.280]$} & 0.3206 \\
\hline \multicolumn{5}{|l|}{ Education Level } \\
\hline Never been to School & Reference & Reference & Reference & Reference \\
\hline Partial Primary & $1.0549(0.4111)$ & 2.872 & {$[1.283-6.427]$} & 0.0103 \\
\hline Partial Secondary & $-0.1680(0.6165)$ & 0.845 & {$[0.253-2.830]$} & 0.7852 \\
\hline Secondary & $-0.1252(0.6125)$ & 0.882 & {$[0.266-2.931]$} & 0.8381 \\
\hline \multicolumn{5}{|l|}{ Occupation } \\
\hline Peasant & Reference & Reference & Reference & Reference \\
\hline House wife & $0.1445(0.3929)$ & 1.155 & {$[0.535-2.496]$} & 0.7130 \\
\hline Petty trade & $0.0577(0.4086)$ & 1.059 & {$[0.476-2.360]$} & 0.8877 \\
\hline Employed & $0.0217(0.9043)$ & 1.022 & [0.174-6.014] & 0.9809 \\
\hline \multicolumn{5}{|l|}{ Marital Status } \\
\hline Not in Union & Reference & Reference & Reference & Reference \\
\hline In Union & $-0.3620(0.2675)$ & 0.696 & {$[0.412-1.176]$} & 0.1760 \\
\hline
\end{tabular}

\subsection{Qualitative Results}

\subsubsection{Crops Which Are Mostly Contaminated by Aflatoxins}

With regard to the awareness issue, researcher also wanted to explore if people are aware of the types of crops which are highly susceptible to aflatoxin contamination. Most of the participants who were interviewed in various areas visited mentioned cereal crops as the most vulnerable to aflatoxin contamination. Most of them mentioned maize, sorghum, cassava, uwele but some of them mentioned even onions as among the crops which are vulnerable to aflatoxin contamination.

One participant alleged that;
"For these mold or fungus (aflatoxins), us who cultivate sorghum, maize and millet (uwele) I can say these crops are the most vulnerable to these aflatoxins and at most times these (fungus) aflatoxins comes when these crops are growing"-FGD male Chamwino

In another interview, another participant alleged that; ........."Crops which are most vulnerable includes maize, millet, sorghum and for example millet once contaminated instead of being white in colour they become blackish, for the case of maize once contaminated then when you peel it you will find molds/fungi inside so these are the problems for our crops we don't have any other problem"-FGD female Bahi 


\subsubsection{Causes of Aflatoxins (Fungi) Found in Crops or Grains That Are Used as Food for Adults or Your Infants}

As part of exploration of knowledge to aflatoxin contamination, researcher wanted to see if people in the community know the causes of these aflatoxin contaminations. From the interviews which were conducted, people in the community are aware of the causes and most of them mentioned moisture as the most common cause of aflatoxin contamination, most people explained that when crops are either stored for a long time or when are stored not fully dry always develop these moulds or fungus or aflatoxins.

In one of the Focus group discussion conducted, one respondent said;

"It is caused by moisture, and most cases it is caused when the cloud is heavy with signs of rainfall... if you store crops during such time there is high chance for the crops to be contaminated"'-FGD male and female Ikungi

Another respondent from another focus group discussion alleged that;

"In most cases it is moisture that causes this fungus to develop or when you store crops when not fully dry and also when these crops stay in the ghala for a very long time"-FGD male Chamwino

\subsubsection{Community Actions to prevent Aflatoxins Contamination in Complementary Foods}

When asked about things which they do to prevent aflatoxins contamination in the complementary food most people mentioned the same kind of precautions they usually take to prevent aflatoxins in general. People mentioned drying of crops before taking them inside for storage, use of medication to spray on the crops before and during storage, taking crops outside regularly in between storage time and storing crops in the rooms which are well ventilated and sun rays normally gets in and out daily and easily. Some people mentioned that, storage inside or outside depends on the type of crop some crops they never take them inside because even if they take them while dry they can get moisture easily so those kind of crops are normally stored outside on the roofs during summer.

........"We usually buy medicine and spry to the crops before taking them inside for storage and sometimes if we don't have enough money we just keep them outside for a while and then take them back inside for storage"- FGD male Chamwino

Aflatoxins contamination has a very big and detrimental effects to the life of people in the community because when the food or crops are contaminated by these fungi the food is no longer good for consumption neither selling so the farmer gets double loss and this is what makes most people motivated to prevent the aflatoxin contamination.

\section{Discussion}

Contamination of complementary foods by aflatoxin is a serious public health threat that requires attention to ensure that proper actions are taken to limit its health effects. Although aflatoxin is a controllable risk factor in the diets, people are still not aware about its presence and consequences to health. In a study conducted by Ngoma et al. [42] $82.0 \%$ of the parents were not aware of aflatoxin contamination in complementary foods and its health effects. Recent findings [43] also indicate that parents who are responsible for preparation of complementary foods in the central regions of Tanzania do not fully perceive aflatoxins as being harmful to human and animals and their attitude towards their control was low, in general.

The study has identified a number of issues related to parents' local barriers that may cause a lack of action, and the benefits of controlling aflatoxin contamination in complementary foods. In the current study, the respondents who were aged above 34 years old were less likely to apply traditional fungicides/pesticides for storing crops which is very useful in controlling food insecurity at household level than parents aged less or equal to 34 years old. The relatively less number of times used to traditional fungicides/pesticides by parents aged above 34 years old could be partially attributed to the fact that a larger proportion of this group also indicated attainment of no or low levels of formal education. This finding is similar to the study done by Ngongi, [44] in Tanzania which showed that as age of the respondents' increases, food insecurity at household level also increases. These findings are also in line with those from the study by Babatunde et al. [45] which show that vulnerability to food insecurity increases as the age of the household head increases. Again, the study done by Idrisa et al. [46] has also showed that age, in relation with farming experience has a significant influence on the decision making process of farmers with respect to risk aversion, implementation of improved good agricultural skills, and other production related decisions. It was concluded that, poor storage methods and structure and poor treatment of food crops during storage resulted to loss of food stored due to pest and molds/fungi could be one of factors leading to food insecurity and safety in the study area.

Costs involved is the barrier for proper processing of grains/nuts to reduce spoilage/aflatoxin/mould (fangasi) at home while time consumed and reduced food quantity had equal proportions. Parents felt that proper processing like winnowing, washing, sorting, and dehulling of grains/nuts to reduce aflatoxin was too costly in terms of money. It was revealed that the families with 3-7 children were less likely to report that time consumed in the process was the barrier rather than the costs involved in comparison to the families with 1-2 children. On the other hand, families with 3-7 children reported that processing of grains/nuts to reduce aflatoxin was reducing food quantity to the family in comparison with families of 1-2 children. Parents claimed that washing, winnowing, sorting and dehulling of crops might reduce food quantity to the family. Normally, the larger the family size, the more likely the farmer is to become successful as the household has more labour to work on the 
farm. However, this would only work if all family members are old enough to perform the farm work, otherwise if the household size consists of majority of young children who cannot be used as family labour, it would not work. The household size can influence food security at household level. Food insecurity increases as household size increases. Households with one or two members have the least percentage of food insecurity as long as the members are not elderly or small children. Households with 7 members are more vulnerable to food insecurity compared to those with fewer members [47]. In the present study, the big number of children in the families and food shortage may lead them to eat contaminated foods with mycotoxins which are harmful to their health.

In this study, parents with partial and primary school education were more willing to use local pesticides or fungicides during storage of crops to control fungi/ mould than never been to school parents. Dosman et al. [48] in Canada reported that people with higher levels of education are likely to be better informed, and therefore, may be more aware of some types of risk of food additives or pesticides residual in food than people with less education. People with higher education levels generally demand for food safety and security. [49] revealed that those with the highest levels of education were more willing to pay for food safety. Furthermore, education is very important in raising awareness; however in the current study, no formal or informal education were provided in the community about aflatoxin contamination, its health effects or control in crops used as ingredients in preparation of complementary foods. Therefore, in this study, very few parents were using good post-harvest practices, but majority of them were using poor post-harvest practices hence making them eat susceptible crops which might be contaminated with aflatoxins. These findings are similar to the study done by [50] in Mtwara, Tanzania, which indicated that majority of the household respondents that is, $86.7 \%$ did not receive any extension services (education) for the whole season. Lack of extension services to the farmers was also reported by [51] on agriculture development and food security in Tanzania. In this case, it constrained access to inputs and timely advice to stakeholders, particularly smallholder farmers and to a large extent impedes progress in the intensification of agriculture.

\section{Conclusions and Recommendations}

The respondents in the study areas admitted that costs was the barrier for proper processing of grains/nuts which were used as an ingredients in preparation of complementary foods to reduce spoilage/aflatoxin/mould/fungus (fangasi) at home while time consumed and reduced food quantity had equal proportions. Parents felt that proper processing like winnowing, washing, sorting, and dehulling of grains/nuts to reduce aflatoxin was too costly in terms of money. The question of food safety, food security and awareness of its contamination remains essential to global public health. Thus, strengthening food safety measures will help minimize the burden of food borne diseases, reduce poverty and contribute to the achievement of the Sustainable Development Goals. Therefore, the government should help in the management of mycotoxins and provision of food security for the community. Comprehensive public awareness efforts should be made on the food safety and prevention of food borne diseases especially those which are caused by fungi/aflatoxins. This study suggests that the community members in the study areas show unsatisfactory level of good agricultural practices. However, further studies need to be conducted to assess the burden of aflatoxicosis in this community and also the common storage practices, as well as chemicals involved. Thus, it is important that the people continue to be educated on good agricultural practices, awareness and health behaviours with respect to food safety.

\section{Funding}

This work was partly privately funded by Dr. Selestin Joseph Ngoma as part of my $\mathrm{PhD}$ program at Sokoine University of Agriculture, Morogoro, Tanzania and The University of Dodoma through Higher Education Students Loans Board (HESLB).

\section{Competing Interests}

The authors declare that they have no competing interests.

\section{Acknowledgements}

The authors express sincere thanks to all who helped in the execution of the study especially the staff members of the Department of Food Technology, Nutrition and Consumer Sciences, Sokoine University of Agriculture, Morogoro, Tanzania.

\section{References}

[1] CAST (Council for Agriculture Science and Technology). 2003. Mycotoxins: Risks in plant, animal and human systems. Taskforce Report No. 139. Ames, IA: Council for Agriculture, Science and Technology.

[2] Wild, C. P. and Gong, Y. Y., 2010. Mycotoxins and human disease: A largely ignored global health issue. International Agency for Research on Cancer, 69372 Lyon Cedex 08, France and Molecular Epidemiology Unit, LIGHT Laboratories, University of Leeds, Leeds, LS2 9JT, UK. Carcinog vol. 31 No. 1 pp. 71-82, 2010.

[3] Pitt, J. I. and Miller, J. D., 2017. A concise history of mycotoxin research. Journal of Agricultural and Food Chemistry65: 7021-7033.

[4] Kamala, A., Shirima, C., Jani, B., Bakari, M., Sillo, H., Rusibamayila, N., De Saeger, S., Kimanya, M., Gong, Y. Y., Simba, A., The investigation team. 2018. Outbreak of an acute aflatoxicosis in Tanzania during 2016. Special issue: Mycotoxin in Africa. World Mycotoxin Journal 11 (3): 311320. 
[5] Bennett, J. W. and Klich, M. 2003. Mycotoxins. Clinic Microbiological Review16: 497-516.

[6] Strosnider, H., Hell, K., Henry, S. H., Jeffers, D., Jolly, C., Jolly, P., Kibata, G. N., Lewis, L., Liu, X., Luber, G., McCoy, L., Azziz-Baumgartner, E., Mensah, P., Miraglia, M., Misore, A., Njapau, H., Ong, C. N., Onsongo, M. T. K., Page, S. W., Park, D., Patel, M., Phillips, T., Banziger, M., Pineiro, M., Pronczuk, J., Rogers, H. S., Rubin, C., Sabino, M., Schaafsma, A., Shephard, G., Stroka, J., Wild, C., Williams, J. T., Bhat, R. V., Wilson, D., Breiman, R., Brune, M. N., Decock, K., Dilley, A., Groopman, J. 2006. 'Workgroup report: Public health strategies for reducing aflatoxin exposure in developing countries', Environmental Health Perspec114: 1898-1903.

[7] Ephrem, G. 2015. Implication of Aflatoxin Contamination in Agricultural Products American Journal Food Nutrition Vol. 3, No. 1, 12-20.

[8] Magembe, K. S., Mwatawala, M. W., Mamiro, D. P., Chingonikaya, E. E. 2016. Assessment of awareness of mycotoxins infections in stored maize (Zea mays L.) and groundnut (arachis hypogea L.) in Kilosa District, Tanzania. International Journal of Food Contamination 3: 12 DOI 10.1186/s40550-016-0035-5.

[9] Williams, J. H., Phillips, T. D., Jolly, P. E., Stiles, J. K., Jolly, C. M., Aggarwal, D. 2004. Human aflatoxicosis in developing countries: a review of toxicology, exposure, potential health consequences, and interventions. American Journal Clinic Nutrition80: 1106-1122.

[10] WHO (World Health Organisation). 2006. Global Environment Monitoring System-Food Contamination Monitoring and Assessment Programme (GEMS/Food). [http://www.who.int/foodsafety/chem/gems/en/index1.html] site visited on $09 / 05 / 2015$.

[11] Gong, Y. Y., Turner, P. C., Hall, A. J., Wild, C. P. 2008. Aflatoxin exposure and impaired child growth in West Africa: An unexplored international public health burden? In: Mycotoxins: Detection Methods, Management, Public Health and Agricultural Trade, (Leslie JF, Bandyopadhyay R, Visconti A, editors). Oxfordshire, UK: CAB International p5365 .

[12] Jolly, P. E., Shuaib, F. M., Jiang, Y., Preko, P., Baidoo, J., Stiles, J. K., Wang, J. S., Phillips, T. D., Williams, J. H. 2011. Association of high viral load and abnormal liver function with high aflatoxin B1-albumin adduct levels in HIV-positive Ghanaians: preliminary observations. Food Additive Contaminants Part A 28: 1224-1234.

[13] Jolly, P. E., Inusah, S., Lu, B., Ellis, W. O., Nyarko, A., Phillips, T. D., Williams, J. H. 2013. Association between high aflatoxin B1 levels and high viral load in HIV-positive people. World Mycotoxin Journal6: 255-261.

[14] Joens, L. A., Pier, A. C., Cutlip, R. C. 1981. Effects of aflatoxin composition on the clinical course of swine dysentery. American Journal of Veterinary Research 42: 11701172 .

[15] Fernandez, A., Belio, R., Ramos, J. J., Sanz, M. C., Saez, T. 1997. Aflatoxins and their metabolites in the tissues, faeces and urine from lambs feeding on an aflatoxin-contaminated diet. Journal of Sciences, Food and Agriculture 74: 161-168.

[16] Kang'ethe, E. K. and Lang'a, K. A. 2009. Aflatoxin B1 and M1 contamination of animal feeds and milk from urban centers in Kenya. African Health Sciences 9: 218-226.
[17] Caloni, F and Cortinovis, C. 2010. Toxicological effects of aflatoxins in horses. The Veterinary Journal doi: 10.1016/j.tvj1.2010.06.002.

[18] Cotty, P. J. and Ramon, J. G. 2007. Influences of climate on aflatoxin producing fungi and aflatoxin contamination. International Journal Food Microbiology 119: 109-115.

[19] (NTP) National Toxicology Program. 2011. Aflatoxins; Known to be human carcinogens, Report on Carcinogens Twelfth Edition, Department of Human and Human Services, CAS No. 1402-68-2.

[20] Kamala, A., Kimanya, M., Haesaert, G., Tiisekwa, B., Madege, R., Degraeve, S., Cyprian, C., De Meulenaer, B. 2016. Local post-harvest practices associated with aflatoxin and fumonisin contamination of maize in three agro ecological zones of Tanzania. Food Additive Contaminants Part A 33: 551-559.

[21] CDC (Center for Disease Control and Prevention). 2004. Outbreak of aflatoxin poisoning in eastern and central provinces, Kenya, January-June 2004. MMWR 53 (34): 790793.

[22] Probst, C., Bandyopadhyay., R, Cotty, J. 2013. Diversity of aflatoxin-producing fungi and their impact on food safetyin sub-Saharan Africa. International Journal Food Microbiology 174 (2014): 113-122.

[23] De Koe, W. J. 1999. Regulations of the European Union for mycotoxins in foods. ArhHig Rada Toksikol 50: 37-46.

[24] Creppy, E. E. 2002. Update of survey, regulation and toxic effects of mycotoxins in Europe. Toxicol Letter 28 (127): 1928 .

[25] CEC (Commission of the European Communities). 2006. European Commission Regulation 1881/2006.19.12.2006. Bruxelles: Official Journal of the European Commission L364/5-24.

[26] EMAN, (European Mycotoxins Awareness Network). 2012. Limits for Aflatoxin $\mathrm{M}_{1}$ by Countries, Mycotoxins Legislation Worldwide. Available at: http://www.mycotoxins.org/.

[27] IARC (International Agency for Research on Cancer). 2002. Some traditional herbal medicines, some mycotoxins, naphthalene and styrene. IARC monographs on the evaluation of carcinogenic risks to humans (vol. 82). Lyon, France: World Health Organization, p. 1-556.

[28] IARC (International Agency for Research on Cancer).1993. Chemicals, groups of chemicals, complex mixtures, physical and biological agents and exposure circumstances to be evaluated in Future IARC Monogr, Report of an ad-hoc Working Group (IARC intern. Rep. No. 93/005).

[29] IARC (International Agency for Research on Cancer). 2012. Agents Classified by the IARC Monogr. Vol. 1, No. 104.

[30] Kamala, A., Ortiz, J., Kimanya, M. E., Haesaert, G., Donoso, S., Tiisekwa, B., De Meulenaer, B. 2015. Multiple mycotoxin co-occurrence in maize grown in three agro-ecological zones of Tanzania. Food Contaminant 54: 208-215.

[31] Kimanya, M. E., De Meulenaer, B., Tiisekwa, B., NdomondoSigonda, M., Devlieghere, F., Van Camp, J. 2008. Cooccurrence of fumonisins with aflatoxins in home-stored maize for human consumption in rural villages of Tanzania. Food Additive Contaminants Part A Chemical Analytical Control Exposure Risk Assessment 25: 1353-1364. 
[32] Kimanya, M. E., De Meulenaer, B., Tiisekwa, B., Ugullum, C., Devlieghere, F., Van Camp, J., Samapundo, S., Kolsteren, P. 2009. Fumonisins exposure from freshly harvested and stored maize and its relationship with traditional agronomic practices in Rombo district, Tanzania. Food Additive Contaminants Part A. 26: 1199-1208.

[33] Shirima, C. P., Kimanya, M. E., Routledge, M. N., Srey, C., Kinabo, J. L., Humpf, H. U., Wild, C. P., Tu, Y. K, Gong, Y. Y. 2015. A prospective study of growth and biomarkers of exposure to aflatoxin and fumonisin during early childhood in Tanzania. Environmental Health Perspectives 123: 173-178.

[34] Magoha, H., Kimanya, M., De Meulenaer, B., Roberfroid, D., Lachat, C., Kolsteren, P. 2014b. Risk of dietary exposure to aflatoxins and fumonisins in infants less than 6 months of age in Rombo, Northern Tanzania. Maternal Child Nutrition Doi: 10.1111/men.12155.

[35] Magoha, H., De Meulenaer, B., Kimanya, M., Hipolite, D., Lachat, C., Kolsteren, P. 2014a. Fumonisin B1 contamination in breast milk and its exposure in infants under six months of age in Rombo, Northern Tanzania. Food Chemical Toxicological 74: 112-116.

[36] Buguzi, S. 2016. 'Tanzania: Food poisoning linked to 14 deaths in two regions. The Citizen [online], 20 July 2016. [http://allafrica.com/stories/201607290685.html] site visited on $18 / 09 / 2016$.

[37] Magnani, R. 1997. Sampling Guide.

[38] Dean, A. G., Dean, J. A., Coulombier, D., Burton, A. H., Brendel, K. A., Smith, D. C., Dicker, R. C., Sullivan, K. M., Robert, F., Fagan, R. F. 1996. Epi Info, Version 6 A WordProcessing, Database, and Statistics Program for Public Health on IBM-compatible Microcomputers Program design.

[39] Jolly, C. M., Bayard, B., Awuah, R. T., Fialor, S. C. and Williams, J. T. (2009). Examining the structure of awareness and perceptions of groundnuts aflatoxin among Ghanaian health and agricultural professionals and its influence on their actions. Journal of Socio-Economics 38: 280-287.

[40] Krueger, R. A. and Casey, M. A. 2015. Focus groups; A practical guide for applied research, $5^{\text {th }}$ Edition. India, SAGE Publications Asia-Pacific Pte. Ltd.

[41] Hancock, B. 1998. Trent Focus for Research and Development in Primary Health Care. An Introduction to Qualitative Research. Division of General Practice, Focus Group.
[42] Ngoma, S., Tiisekwa, B., Mwaseba, D., Kimanya, M. 2016. Awareness of Aflatoxin Health Risks among Parents with Children Aged Between 6-23 Months in Central Tanzania. International Journal of Nutrition and Food Sciences 5 (6): 429-436.

[43] Ngoma, S. J., Kimanya, M., Tiisekwa, B. and Mwaseba, D. 2017. Perception and Attitude of Parents towards Aflatoxins Contamination in Complementary Foods and Its Management in Central Tanzania. The Journal of Middle East and North Africa Sciences, 3 (3): 6-21. (P-ISSN 2412-9763)-(e-ISSN 2412-8937). www.jomenas.org.

[44] Ngongi, A. M. 2013. Food Insecurity and Coping Strategies of Farm Households in Kahama District, Tanzania. A dissertation submitted in partial fulfillment of the requirements for the Degree of Master of Arts in Rural Development of Sokoine University of Agriculture, Morogoro, Tanzania.

[45] Babatunde, R. O., Omotosho, O. A., Ololunsanya, E. O., Owoloki, G. M. 2008. Determinants of vulnerability to food insecurity: A gender analysis of farming household in Nigeria. Journal of Agricultural Economics 63 (1): 116-125.

[46] Idrisa, Y. L., Gwary, M. M. and Shehu, H. 2008. Analysis of food security status among farming households. Journal of Tropic Agriculture, Food and Environmental Extensions7 (3): 199-205.

[47] Chanetsa, J., Vhurmuku, E., Tarakidzwa, A. 2003. Zimbabwe Urban Areas food Security and Vulnerability Assessment; Ministry of Agriculture- National Early Warning Unit, September 2003, Harare, Zimbabwe. p. 33.

[48] Dosman, D. M., Adamowicz, W. L., Hrudey, S. E. 2001. Socioeconomic determinants of health and food safety-related risk perceptions. Risk Analysis 21: 307-317.

[49] Baker, G. A. 2003. Food safety and fear: factors affecting consumer response to food safety risk. International Food and Agribusiness Management Review 6: 1-11.

[50] Barago, D. K. 2013. Factors Affecting Household Food Security: A Case Study of Mtwara Rural District-Mtwara Region. A Dissertation Submitted in Partial Fulfillment for the Requirements for Degree of Master of Arts in Social Work of the Open University of Tanzania.

[51] Amani, H. K. R. 2004. Agricultural Development and Food Security in Sub Saharan Africa., Tanzania Country Report. Economic and Social Research Foundation (ESRF) Dar es Salaam, Tanzania. August 2004. 31pp, 45pp. 